\title{
MAGIA, CIENCIA Y RELIGIÓN EN ANTROPOLOGÍA SOCIAL. DE TYLOR A LEVI-STRAUSS
}

\author{
Ismael Apud \\ Universidad de la República, Montevideo
}

\begin{abstract}
Resumen.- El siguiente trabajo tiene como objetivo explorar el discurso antropológico moderno sobre la religión y sus prácticas relacionadas (mitos, ritos, magia), describiendo cómo se construye dicha noción en oposición al pensamiento científico (y por ende, al pensamiento antropológico mismo), y qué concepciones culturales y psicológicas están implicadas en ello. En un recorte de lo que de otro modo habría sido inabarcable, la decisión pasó por abordar la temática desde la clásica filiación Tylor-Frazer-Durkheim-Malinowski-Levi-Strauss. Veremos como bajo una concepción positivista de base, traza bajo una línea argumentativa evolucionista, una escala gradual de desarrollo histórico, que supone una supremacía "etnocéntrica" de la cultura occidental.
\end{abstract}

Palabras clave.- religión, antropología social, ciencia, magia

\section{Magic, Science and Religion in Social Anthropology. From Tylor to Levi-Strauss}

\begin{abstract}
The following study aims to explore the modern anthropological discourse on religion and its practices (myths, rituals, magic), describing how was built such notion in opposition to the scientific knowledge (and therefore the anthropological knowledge too), and what cultural and psychological concepts are involved in it. In a cut of what would otherwise have been overwhelming, the decision went to address the issue from the classic filiation Tylor-FrazerDurkheim, Malinowski, Levi-Strauss. A positivist conception is the basic line of argument; an evolutionary discourse which concieves an historical development, and a "ethnocentric" supremacy of Western culture.
\end{abstract}

Keywords.- religion, social anthropology, science, religion

\section{Introducción}

La ciencia de la religión (Religionwissenschaft) se conforma como disciplina independiente en la segunda mitad de siglo XIX, con pioneros como Max Müller o Sir Edward Burnett Tylor. Surgen en ese entonces diversas cátedras y estudios:

"En 1873, Ginebra estableció la primer cátedra académica de religión en Europa; tres años más tarde, los Países Bajos establecieron cuatro; en 1879, el Collage de France, en París, dotó una; y, en 1885, la Sorbona fundó la primera facultad de religión independiente." (De Waal, 1975, p. 59-60).

Separada de la teología y de las variadas corrientes filosóficas de la época, la naciente ciencia de la religión se proponía un análisis comparativo de mitos y creencias, mediante genealogías (por lo general bajo la influencia de métodos filológicos) o bien secuencias evolutivas, teñidas del "eurocentrismo" característico de la época. Este eurocentrismo evolucionista ofrecía un modelo escalonado (por lo general tripartito) donde, desde la oscura ignorancia del "salvajismo", la humanidad se apropiaba en el correr de la historia de la luz de un conocimiento que la llevaba al uso pleno de la razón, así como al 
conocimiento de sí mismo y de la naturaleza. Dicha estructura escatológica es reiterativa, tanto en autores como Lewis Henry Morgan (salvajismo, barbarie, civilización) o Augusto Comte (etapa teológica, metafísica y positiva) entre otros. En la mayoría de los casos el modelo se establece en base a una escatología de la razón, típica de una modernidad de espíritu "kantiano":

“... pese a sus apariencias biologistas, la etnología evolutiva partía de un racionalismo de base, cuyas raíces se remontan, al menos, a Kant y sus postulados sobre la identidad del espíritu humano, que Comte y su escuela positiva transformarán en la universalidad de la naturaleza humana." (Carracedo, 1975, p. 27)

No es de extrañarnos que este tipo de concepciones finalistas resuenen aún con fuerza en los diversos avatares que transmigran ideológicamente por los campos políticos y científicos, bajo los ideales de progreso, democracia, así como en el marco de disciplinas como la psiquiatría y el psicoanálisis. Es bajo esta concepción evolucionista donde la antropología y la etnología comienzan a diferenciarse como disciplinas autónomas.

\section{Tylor y el animismo}

Sir Edward Burnett Tylor (1832-1917) fue el primer titular de una cátedra de antropología en Gran Bretaña (1896) así como el primer autor de un tratado de antropología general, Primitive Culture (1871). Sus ideas parten de un esquema evolutivo donde bajo el influjo racionalista de la época, otorga una unicidad instrumental a la cognición humana, superpuesta a un eje temporal donde la organización social y la cognición recorren un progresivo desarrollo hacia las formas actuales de la razón, tanto en lo moral como en lo científico:

"El afán del hombre por conocer las causas actuantes en cada hecho del que es testigo, las razones por las que cada estado de cosas que él observa es como es y no de otro modo, no constituyen un producto de alta civilización, sino una característica de su especie hasta en las fases más bajas. Entre los salvajes primitivos hay un apetito intelectual cuya satisfacción requiere muchos de los momentos no acaparados por la guerra o por el juego, por el sueño o la necesidad de alimentarse." (Tylor, 1977, p. 345-346)

Se trata de una reivindicación del "primitivo", si tomamos en cuenta ciertos prejuicios de la época. El primitivo deja de ser un ignorante presa del error, para ser parte de un eslabón necesario en la cadena evolutiva de la razón y el orden social. Relativizado su valor en función de su situación filogenética, su inferioridad transmuta en virtud, y sus logros en un paso esencial para la adquisición de la ciencia y los valores occidentales. Esta concepción posiciona las creencias del "salvaje" actual bajo el rótulo de "supervivencias" de antiguos hábitos culturales, coagulados en el fluir de un progreso humano cuyo cenit sólo puede encontrarse en occidente. Serían un reflejo cristalizado de tiempos en los que el hombre no había alcanzado aún cierto nivel cultural. Dicho reflejo posibilitaba una mayor comprensión del desarrollo de la razón en su progresivo avance cognitivo sobre los terrenos oscuros de la naturaleza, a 
través de disciplinas como la antropología y la etnología. El salvaje era una especie de "fósil vivo", y la antropología un estudio "arqueológico" de una cultura paradójicamente viva y muerta: fosilizada en su desarrollo cognitivocultural, viviente desde lo biológico y psicológico.

Desde esta perspectiva racionalista-positivista, la evolución humana se concibe bajo dos términos fundamentales en el pensamiento científico general. Por un lado la razón, sus categorías y sus formas lógicas. Por el otro la naturaleza, la realidad material sobre la que deposita su fe el positivismo. El progreso de la humanidad consistiría entonces en el despliegue dialéctico del raciocinio sobre la realidad y las necesidades circundantes; dicha dialéctica se configura en base a procesos subjetivos ideativos y su correspondencia con lo "real", concebido en este caso como el conjunto de piezas mecánicas y sus relaciones dadas de por sí en el orden natural. Cada sistema de acción y cognición efectuaría una dialéctica propia a su posición dentro del desarrollo históricocultural. En el caso de la magia, Tylor concibe una ciencia primitiva, donde dominan mecanismos erróneos, pero conteniendo en potencia el afán científico por la búsqueda del conocimiento. El principal error que Tylor atribuye a la magia, es la indistinción que efectúa al no separar discriminadamente los componentes intrasubjetivos (ideativos, imaginarios) de los que llegan al campo perceptivo desde un "afuera" material y objetivo (realidad positiva). Este primer gran error arrastra consigo las cadenas causalísticas generadas por la cognición humana pues, al no efectuar una diferencia cualitativa entre dichos niveles fenomenológicos, el "hilo de Ariadna" producido en la asociación de ideas se pierde en los laberintos de las distintas experiencias humanas:

"La clave principal para la comprensión de la ciencia oculta [la magia] es la de considerarla en la asociación de ideas, una facultad que radica en el fundamento mismo de la razón humana, pero, en no pequeña medida, en la sinrazón humana también. El hombre, que todavía en una baja situación intelectual, tras haber llegado a asociar en el pensamiento aquellas cosas que por experiencia sabe que están relacionadas en la realidad, procedió erróneamente al invertir esta acción, concluyendo que la asociación en el pensamiento debe implicar en la realidad una relación semejante. Así intentó descubrir, vaticinar y producir acontecimientos por medio de procesos que nosotros ahora podemos ver que solo tienen un significado ideal. Por un gran volumen de testimonios de la vida salvaje, de la bárbara y de la civilizada, las artes mágicas resultantes de esta errónea conducta de tomar un ideal por una relación real pueden ser claramente seguidas desde la cultura inferior de la cual han surgido hasta la cultura superior en que actualmente se encuentran." (Tylor, 1977, p. 122).

Vemos como la confusión entre los componentes ideativos y la realidad generan un sistema de causalidades erróneo ya que, pese a que se establecen relaciones totalmente válidas en su aspecto formal, no se distinguen las significaciones imaginarias de las elaboradas en el campo de lo realperceptivo, distorsionándose la relación dialéctica con el mundo, como sucede cuando el neurótico no es capaz de elaborar un principio de realidad que escape de las producciones fantasmáticas subyacentes en su inconciente. El pensamiento primitivo no ha podido por lo tanto efectuar una discriminación 
coherente entre lo real y lo imaginario. No es de extrañar entonces que Freud, bajo esas mismas condiciones epistémicas e influenciado por el pensamiento de la época, homologara el desarrollo filogenético al ontogenético, así como las configuraciones neurótico-obsesivas con el ritual y las producciones míticas del primitivo. Es característico en el pensamiento psicoanalítico, concebir lo patógeno como irrupción del proceso primario (íntimamente ligado a las producciones fantasmáticas e imaginarias) sobre el secundario (lógica y principio de realidad).

Es bajo este hilo discursivo que Tylor plantea su definición mínima de religión como "creencia en seres espirituales", introduciendo en el vocabulario antropológico la noción de animismo, punto clave sobre el que se tejen y desarrollan las diversas tramas mitológicas y teológicas. El animismo incluiría toda clase de seres espirituales, aunque sentaría sus bases en la creencia del alma humana. Dicha creencia, responde a una necesidad de explicar ciertas experiencias donde lo corporal y lo subjetivo parecen no poseer una correspondencia exacta. El primitivo se halla ante la encrucijada de establecer ciertas relaciones lógicas entre el sueño y la vigilia, la vida y la muerte, el trance y la conciencia ordinaria. Como es incapaz de discriminar lo imaginario y lo real como campos heterogéneos, debe explicar aquellas experiencias donde la conciencia parece desligarse de las sujeciones corporales y materiales recurriendo a una suerte de "ontologización" de sus propias producciones oníricas, en especial aquellas en las que se ve a sí mismo. Surge entonces la creencia en un alma humana, que puede separarse temporalmente del cuerpo bajo la influencia del sueño, o bien romper definitivamente sus lazos en el momento de la muerte. Y surge entonces la religión, como producto de una especulación en torno a la naturaleza de determinados fenómenos fisiológicos y psíquicos, sobre los cuales el primitivo establece distinciones erróneas, que no contemplan la diferencia entre lo real y lo imaginario.

A partir de la noción de animismo, Tylor establece extrapolaciones que permiten la utilización de este mismo recurso en otros seres y elementos de la naturaleza. A medida que transcurre la cadena de analogías comienza a desarrollarse un sistema religioso strictu sensu, lo cual posibilita la formación de doctrinas y rituales comunitarios, así como un método para explicar al ser humano y a la naturaleza. Detrás de todo este desarrollo aparentemente "irracional", Tylor ve un esfuerzo intelectual que implica la utilización correcta de mecanismos lógicos aplicados sobre premisas incorrectas, fruto de una percepción inadecuada de lo real. Sin embargo, la propia dialéctica razónrealidad lleva al hombre y a la cultura a un progresivo desarrollo y a una percepción adecuada de la naturaleza. Recurre entonces al clásico escalonamiento tripartito donde, a partir de un primer momento animista, se desarrolla por propagación analógica una segunda etapa politeísta. Ciertas almas son elevadas al rango de dioses, adjudicándoseles poderes de la naturaleza y, cuando un dios llega a dominar la escala jerárquica, se llega finalmente a la última gran etapa: el monoteísmo. Tylor establece entonces una teoría evolucionista de la razón y su desarrollo progresivo, donde la religión es solamente contemplada en sus aspectos cognoscitivos, en una suerte de dialéctica con la realidad, dejando a un lado su eficacia en la "cohesión social" o bien en las relaciones de poder. 


\section{La rama dorada de Frazer}

Es leyendo a Tylor y su Primitive Culture, que Sir James George Frazer (18541941) descubre su pasión por la antropología. Su obra más importante, La Rama Dorada (1898) ha sido de enorme influencia en autores tan diversos como Malinowski, Wittgenstein o Freud. Se trata de una obra de gabinete, aunque de gran importancia como recopilación etnográfica. A nivel teórico, el trabajo de Frazer retoma las concepciones tylorianas, aunque con ciertas modificaciones importantes.

Según Frazer, ya desde el comienzo el hombre utiliza dos formas de pensar la naturaleza. Por un lado un mundo cuya mecánica se compone de agentes sobrenaturales -"...seres personales que actúan por impulsos y motivos semejantes a los suyos propios..." (Frazer, 1998, p. 33)-; una especie de proyección masiva sobre la realidad, que atribuiría tanto a seres vivos como a objetos materiales las mismas propiedades e intenciones que las internas propias. Se trataría de un pensamiento característico del animismo, y derivaría posteriormente en la complejidad de las formas religiosas:

"Junto a este concepto de un mundo impregnado de fuerzas espirituales, el hombre salvaje posee otro distinto y probablemente más antiguo, en el cual pueden llegar a encontrarse rudimentos de la idea moderna de ley natural, o sea la visión de la naturaleza como una serie de acontecimientos que ocurren en orden invariable y sin intervención de agentes personales." (Ibid., p. 33).

Bajo este pensamiento impersonal de las fuerzas naturales surge entonces la magia, cuyos principios presagian y abren la posibilidad de una futura ciencia. Tenemos entonces dos clases de pensamiento que desde tiempos pretéritos deambularían por el universo conceptual construido por el hombre: uno proyectivo, egocentrista (en términos piagetianos) y animista; otro abstracto, realista e impersonal.

Sin embargo la magia sería una pseudociencia, en el sentido que concibe un orden y una uniformidad impersonal en la naturaleza pero, al igual que en Tylor, yerra en sus leyes específicas, izando sus velas hacia los mares de la ignorancia. Frazer la denomina "magia simpatética", pues actúa mediante "simpatía" común o atracción secreta entre dos cuerpos, sea por una identidad formal-espacial (semejanza), sea por una relación causal-temporal (contigüidad). En base a estos últimos principios, Frazer distingue entre "magia homeopática" donde la ley de semejanza afecta y encadena los cuerpos, y la "magia contaminante" que, bajo la ley de contagio o contigüidad, establece ciertas afecciones entre elementos que estuvieron anteriormente en contacto. En base a dichos principios la magia se consolida como sistema teóricopráctico. Teórico ya que edifica un sistema de leyes -pese a que éstas no posean solidez alguna-, derivando en hipótesis y conclusiones falsas, o sea, en una pseudociencia. Práctico pues establece pautas de comportamiento y relacionamiento con el medio, mediante un sistema de preceptos positivos (encantamientos, ritos) y negativos (tabúes), por lo que la denomina un pseudoarte. Sin embargo y al igual que Tylor, dicho sistema de cogniciónacción posee un valor excepcional si es juzgado desde su posición relativa en 
la escala evolutiva en la que se encuentra inmersa. "Ellos [los primitivos] fueron los predecesores directos, no sólo de nuestros médicos y cirujanos, sino de nuestros investigadores y descubridores en cada una de las ramas de la ciencia natural" (Frazer, 1998, p. 89).

La religión surge bajo la confluencia de concepciones animistas -creencia en seres espirituales superiores que gobiernan la naturaleza y la vida humana- así como la impotencia y esterilidad de la magia frente a la realidad de los procesos naturales. Pues con el correr de la historia "...un tardío reconocimiento de la falsedad inherente a la magia y de su esterilidad puso a la parte más inteligente de la humanidad a meditar una mejor teoría de la naturaleza..." (ibid, p. 83); la magia comienza a desmoronarse como sistema teórico-práctico pues sus leyes generales -sostenidas bajo una especie de proceso primario freudiano- no resistieron más tiempo los duros embates de la realidad. Es en ese momento, cuando el hombre primitivo, "...cortando a la ventura sus antiguas amarras y dejándose llevar por el proceloso mar de la duda y la incertidumbre, sacudía rudamente la feliz confianza de antes en sí mismo y en sus fuerzas" (ibid, p. 84). En la pérdida de su omnipotencia y seguridad, sostenida bajo los cimientos de sus concepciones egocéntricas, se ve forzado a plantearse nuevas hipótesis. Y así concluye que "...si el universo caminaba sin su ayuda ni la de sus compañeros, de seguro que ello se debía a otros seres semejantes a él, pero más poderosos, eran los que invisiblemente dirigían su curso y producían toda la serie de acontecimientos diversos que hasta entonces creyó dependientes de su propia magia"(ibid., p. 84- 85). Es a partir de allí que comienza la hegemonía de los dioses sobre los procesos impersonales, así como la sustitución de la hechicería y la magia por el sacerdote y la súplica. Sin embargo, con el progresivo avance histórico de la razón humana en su apropiación dialéctica de las propiedades de lo real, la religión es desplazada nuevamente por un sistema simbólico-cognitivo, de elementos impersonales y abstractos. Esta vez, exorcizada de las falsas analogías simpatéticas que producían fallos y generalizaciones extremas en las cadenas asociativas del pensamiento, surge la ciencia, cuya fidelidad hacia el método hipotético-deductivo, así como su paciente y exacta observación sobre los fenómenos de la realidad (método experimental), aseguran resultados más exactos y verdaderos.

\section{Durkheim, la sociedad y lo sagrado}

Emile Durkheim (1858-1917) es considerado el fundador de la escuela sociológica francesa. Su obra abarca campos muy diversos, entre los cuales se encuentra las Formes élémentaires de la vie religieuse, de gran importancia tanto para la antropología religiosa como para la teoría antropológica general. Su pensamiento continúa la herencia colectivista de pensadores como SaintSimon y Comte, debatiendo y rechazando las ideas individualistas del utilitarismo inglés, principalmente de Spencer, Hobbes y Adam Smith. Para Durkheim los fenómenos sociales no encontrarían su raíz en la psicología individual, por lo que un método introspectivo e individualista es incapaz de iluminar cualquier problemática de orden sociológico. Lo social sobrepasa las disposiciones individuales y sólo puede ser estudiado como "hechos sociales", 
objeto discreto de la naciente sociología, que coacciona y determina al sujeto psicológico desde un afuera irreductible. Bajo esta concepción los individuos no poseerían disposiciones naturales o predeterminadas, que actuarían a modo de una infraestructura psíquica productora de lo social como epifenómeno, sino que sería lo social la causa-función tanto de sí mismo, como de los fenómenos intra e inter subjetivos. El individuo por sí mismo es tan sólo una masa amorfa indiferenciada que es modelada por las fuerzas sociales, que lo transforman en un ser moral, lógico y disciplinado. Se trata de una concepción organicistafuncionalista, donde la sociedad se entiende como un organismo cuyas funciones remiten unas a otras como sistema total de organización. Partiendo de dichos postulados sistémicos y organicistas, cabe preguntarse cómo concebir la religión dentro del sistema social como totalidad. ¿Cuál es su funcionalidad? ¿Cuál es su relevancia dentro del desarrollo histórico de las sociedades? ¿Cuál es su carácter distintivo y esencial? Es entonces que Durkheim escribe Formas elementales de la vida religiosa, donde retoma y critica las concepciones teóricas de autores como Tylor, Frazer, Müller y Robertson Smith, confrontando las conceptualizaciones y problematizaciones de lo religioso elaboradas hasta entonces con sus propias concepciones orgánico-sociales. Para ello utiliza como campo de justificación científica el caso de los aborígenes australianos. Es relevante dicha elección; un tipo de sociedad donde la cohesión social es máxima, donde no existen especialistas religiosos ni conflictos sociales importantes. De esta forma se eluden los principales problemas que aquejan a este tipo de teorías, y que han sido sin lugar a dudas los flancos donde la teoría durkhemiana ha recibido mayores golpes.

Las Formas elementales comienzan cuestionando a Tylor y su hipótesis de la creencia en seres espirituales (animismo) como fuente originaria de las producciones religiosas. Si fuera cierto que el componente esencial en toda religión es dicha creencia, entonces no debería estar ausente en ciertas religiones conocidas. Tal es el caso del budismo y otras religiones de la India, donde Durkheim comienza un análisis escabroso y sin conocimiento profundo del tema. De todas formas la conclusión general sería válida: "La religión sobrepasa, pues, la idea de dioses o de espíritus $y$, consiguientemente, no puede definirse exclusivamente en función de esta última." (Durkheim, 1993:80). De hecho -continúa el autor- la única distinción que puede encontrarse en cualquier religión del globo es la clasificación de los objetos, sean reales o imaginarios, en dos géneros opuestos: lo sagrado y lo profano. Dentro de este esquema, la creencia en seres espirituales sería una aplicación particular de la creencia en un ámbito sagrado, del que derivan. Lo sagrado sería entonces un conjunto de fuerzas impersonales, una especie de flujo o espacio que se ofrece como motor y materia para la composición de clasificaciones y creencias, y cuyo origen sería social. Tal es el caso del totemismo: "...no es la religión de tales animales, o tales hombres, o tales imágenes, sino de una especie de fuerza anónima e impersonal, que se encuentra en cada uno de estos seres, aunque sin confundirse con ninguno de ellos" (ibid., p. 315). Dicha potencia ha tomado diferentes nombres según los distintos pueblos: Wakan en los Sioux, Orenda en los iroqueses, nauala entre los Kwakiutl y mana entre los melanesios. Citemos a su sobrino Marcel Mauss: 
"De la misma manera que la estética se define por la noción de lo bello, las técnicas por el grado de eficiencia, lo económico por la noción de valor, y el derecho por la noción de bien, los fenómenos religiosos o mágicoreligiosos se definen por la noción de lo sagrado. En el conjunto de fuerzas que se llaman místicas -nosotros las llamaremos mana- hay algunas que los son en tal manera que son, por ello mismo, sagradas. Ellas constituyen la religión strictu sensu, por oposición a las otras, que forman la religión lato sensu... La noción de mana se nos presenta como enteramente universal" (Mauss, 1967, p. 326327).

Su verdadera naturaleza sería de carácter social; fuerzas producidas y desplegadas en la formación de colectivos, una especie de pulsión desarrollada a partir de la exaltación propia del encuentro grupal, del sentimiento de pertenencia, que se materializa inscribiéndose en distintos símbolos, creencias, seres espirituales y dioses:

"Como ejercen sobre nosotros una presión de la que somos concientes, necesitamos localizarlas fuera de nosotros... Unas y otras forman en nuestra conciencia dos círculos de estados mentales, diferentes y separados... a un lado queda el mundo de las cosas profanas y al otro el de las cosas sagradas." (Durkheim, 1993, p. 351).

Dicha distinción es indispensable para la formación de sistemas de representación y clasificación, si tomamos en cuenta que los primeros sistemas simbólicos han sido del orden de lo religioso, principalmente el totémico, íntimamente ligado a establecer relaciones de parentesco y alianzas. La unidad instrumental de la razón, sus categorías y juicios, así como la función simbólica y representativa tienen entonces su origen en lo religioso, que tiene a su vez origen en lo social, en la cohesión, en la formación de una realidad colectiva. Por otro lado las sensaciones y percepciones que configuran el espacio y el tiempo sufren una transformación de orden cualitativo que las dispone en una red de secuencias temporales y límites espaciales definidos.

A grandes rasgos, Durkheim intenta demostrar el carácter y origen social de las creencias religiosas, desde las más elementales (el totemismo australiano), hasta las más complejas. El planteo nodal sobre el que gira las Formas elementales es el de la importancia funcional de la religión como sistema de cohesión social. Su tarea dentro de la totalidad del sistema social es mantener la unidad del sistema, mediante la clasificación y el posicionamiento de los distintos individuos en el conjunto de relaciones territoriales e intersubjetivas, reduciendo el conflicto al mínimo. "Una religión es un sistema solidario de creencias y prácticas relativas a cosas sagradas, es decir, separadas, prohibidas, creencias y prácticas que unen en una misma comunidad moral, llamada Iglesia, a todos los que se adhieren a ella." (ibid., p. 98). Pero, como primer sistema simbólico, es también origen de todas las demás formas de pensamiento, incluyendo la ciencia:

"Desde luego, la ciencia las somete a una nueva elaboración antes de utilizarlas; las depura de todos los elementos adventicios y aporta en todos sus avances un espíritu crítico que la religión ignoraba; se rodea de precauciones 
para evitar la 'precipitación y los prejuicios', para dejar de lado las pasiones, las prevenciones y cualquier influencia subjetiva." (ibid., p. 670)

Dentro de este esquema y a diferencia de Frazer, la magia no sería un sistema de pensamiento del que luego derivaría la religión, sino la utilización individual y utilitarista de los mismos preceptos desarrollados por las ideas religiosas. Para ello la magia transgrede muchas veces los límites entre lo sagrado y lo profano, actuando en forma inversa a los preceptos religiosos.

\section{El funcionalismo de Malinowski}

El funcionalismo pragmático de Bronislaw Malinowski (1884-1942) efectúa ciertos giros importantes en la teoría de la religión, estableciendo una metodología contextual y psicofisiológica, dónde todo acto cultural se somete a un análisis situacional (posición de la producción cultural dentro de la vida cotidiana) y funcional (relevancia del mismo en los procesos orgánicos, sean fisiológicos y/o psicológicos). El análisis funcional implica relacionar las producciones narrativas, rituales, tecnológicas y todas las de índole cultural, con mecanismos y necesidades básicas universales -primarias o derivadas- del ser humano como organismo psico-fisiológico inmerso en sociedad. Tenemos por ejemplo la necesidad de alimentación, que se actualiza en formas culturales como los rituales de sacrificio y ofrendas. Estos a su vez tendrían su correlato psicológico (sacralización de la comida en gratitud y dependencia de la providencia) y social (estrechar lazos entre la comunidad en el acto ritual de compartir). Lo mismo sucede con los procesos de desarrollo y crisis a nivel ontogénico-individual, y su regulación mediante formas rituales como la iniciación o los rituales relacionados al parto y el puerperio. Se distinguen entonces la función y la forma, siendo las primeras universales y las segundas sus aplicaciones particulares y culturales, que pueden ser designadas bajo el término de "costumbres". Sin embargo, se trata de una división heurística, válida e imprescindible como abstracción, pero de límites imprecisos en la realidad cultural;

"... no hay actividad humana, individual y colectiva, que podamos considerar como puramente fisiológica, es decir, 'natural' o no regulada. Hasta la respiración, las secreciones internas, la digestión y la circulación se producen dentro del ambiente artificial en condiciones culturalmente determinadas. Los procesos fisiológicos del cuerpo humano son afectados por la ventilación, por la rutina y la calidad de los fenómenos nutritivos, por las condiciones de seguridad o peligro, de satisfacción o ansiedad, de temor o esperanza... Hay una constante interacción entre el organismo y el medio secundario dentro del cual vive, es decir, la cultura" (Malinowski, 1978).

Por otro lado, el análisis contextual permite al funcionalismo escapar de un determinismo monocausal función-costumbres, pues toda forma o costumbre debe ser estudiada tanto en relación a su funcionalidad latente como a su interacción con otros elementos y necesidades contextuales, sobre las que se apoya y establece conexiones e intercambios. 
Desde esta perspectiva la cuestión acerca de la religión se establecería en base a cual es la función psicofisiológica y social de la misma, y cuales son sus diferencias con respecto a otros sistemas práctico-simbólicos, como la ciencia o la magia. Con respecto a éstas últimas el autor disiente de cualquier parentesco entre una y otra. En tanto Frazer ve en la magia una especie de ciencia errónea -pero ciencia en potencia al fin y al cabo-, Malinowski realiza un corte discontinuo entre ambas. Pues, mientras la ciencia se basa en la experiencia universal y su confrontación dialéctica mediante la razón y sus procesos lógicos (una especie de "gobierno del pueblo y su razón"), la magia actúa bajo el peso de la tradición, mediante una mística esotérica transmitida en forma elitista e iniciática. En cuanto a los principios que determinan a ambas, no es suficiente la noción de mana y su similitud con los principios impersonales científicos para establecer una suerte de relación entre ambas:

"La ciencia, incluso la que representa el primitivo saber del salvaje, se basa en la experiencia normal y universal de la vida cotidiana, en la experiencia que el hombre adquiere al luchar con la naturaleza en aras de su supervivencia y seguridad, y está fundamentada en la observación y fijada por la razón. La magia se basa en la experiencia específica de estados emotivos en los que el hombre no observa a la naturaleza, sino a sí mismo y en los que no es la razón sino el juego de emociones sobre el organismo humano el que desvela la verdad. Las teorías del conocimiento son dictadas por la lógica, las de la magia por la asociación de ideas bajo la influencia del deseo" (Malinowski, 1985, p. 97-98).

La ciencia sería entonces una forma que asume el pensamiento ya en los tiempos pretéritos del primitivo aunque, claro está, todavía bajo una forma rudimentaria; una especie de dialéctica entre la razón y la realidad que subsume la emotividad a un segundo plano. Se trata de una razón teleológica que actúa a nivel psíquico de forma análoga al principio de realidad psicoanalítico. La magia por su parte actuaría de forma inversa; aquí la emotividad, el deseo intenso y el principio de placer son los que fijan la metodología de acción sobre la realidad. Su origen no lo encontraríamos en la concepción de mana o fuerzas impersonales sobrenaturales, sino que emergería bajo determinadas situaciones conflictivas desencadenantes de tensiones emotivas, y su intento de control sobre las mismas. Cuando la naturaleza revela al hombre su impotencia en el dominio de determinadas situaciones, éste, en la búsqueda del dominio de su angustia frente a su deseo insatisfecho, intenta desesperadamente cualquier clase de actividad, en una especie de acting-out de corte primario. A partir de allí se desencadenan imágenes, palabras y actos rituales que reducen la angustia originaria mediante una analgésica ilusión de efectividad, reduciendo la tensión fisiológica y restituyendo la armonía psíquica. Se trataría de un mecanismo de defensa similar al de las neurosis obsesivas:

"Dicho brevemente una fuerte experiencia emotiva que desgasta en un flujo de imágenes, palabras y actos de conducta, puramente subjetivos, deja una profundísima convicción de su realidad, como si se tratase de algún logro práctico y positivo, de algo que ha realizado un poder revelado al hombre. Tal poder, nacido de esa obsesión mental y fisiológica, parece hacerse con 
nosotros desde afuera, y al hombre primitivo, o a las mentes crédulas y toscas de toda edad, el hechizo espontáneo, el rito espontáneo y la creencia espontánea en su eficacia han de aparecer como la revelación directa de fuentes externas y, sin duda alguna, impersonales." (Malinowski, 1985, p. 90).

La religión, al igual que la magia, tiene su origen y función en situaciones ligadas a un conflicto deseo-realidad, aunque, mientras que la magia es un arte práctico establecido en una relación medios-fines, la religión es un corpus donde medios y fines se autocontienen a sí mismos. La magia apunta a resultados directos, la religión intenta apropiarse y reducir la angustia sobre cuestiones más existenciales, abstractas o fatales, como la muerte, las crisis en el desarrollo ontogénico, la importancia de la tradición, la cohesión social. Su funcionalidad radica en regular y neutralizar las fuerzas del instinto de autoconservación, impidiendo el accionar centrífugo de dichos impulsos desintegradores mediante su apropiación simbólico-ritual en la tradición y las redes sociales en las que se encuentra inmerso el individuo en cada fase de su vida, brindándole así el don de la integridad mental. De esta forma la tradición ofrece mecanismos de defensa específicos que permiten evitar los peligros del miedo, del desaliento y de la desmoralización:

"El mal, esto es, las fuerzas desintegradotas del destino, se distribuyen así por un sistema de seguridad mutua en el infortunio y en las miserias espirituales. En el abandono de un pariente o un amigo, en las crisis de pubertad, en tiempos de un peligro o calamidad amenazadora, cuando la prosperidad puede usarse para bien o para mal, la religión postula el modo justo de pensar y proceder, y la sociedad acepta tal veredicto y lo repite al unísono." (Malinowski, 1985, p. 72)

Sin embargo, y a diferencia de Durkheim, este planteo de lo religioso como sistema de cohesión social comprendería no sólo su carácter colectivo sino también sus aspectos individuales. Mientras que Durkheim concibe las producciones extáticas o ascéticas como exaltaciones provenientes del fervor social, Malinowski es capaz de formular su carácter individual, enunciando distintas experimentaciones solitarias. Su ámbito excedería entonces el propuesto por Durkheim, aunque no sería capaz de captar la dinámica social en su complejidad propia -lo que lo distancia de planteos como el de RadcliffeBrown-. Pero sobre todo, lo que rechaza Malinowski es la homologación de lo social con lo sagrado, siendo este último considerado como una imagen especular del primero. Los dioses no serían una proyección de la sociedad, o mejor dicho, no abarcarían ni lo social ni lo moral en su totalidad, pues de hecho, la tradición o la cultura son una suma de elementos que abarcan tanto lo sagrado como lo profano, así como las producciones sociales e individuales, las normas y costumbres, las leyendas y los mitos, etc. Tampoco existiría una "fuerza moral" o mana, cuyo origen sería exclusivamente social y sobre el que se constituiría una especie de "alma colectiva", especie de sustancia inmaterial que circula y configura las distintas formas culturales. Dicho principio “... carece de fundamentación fáctica y es contrario a los sanos métodos de la ciencia social" (Malinowski, 1985, p. 63). 


\section{El estructuralismo de Levi-Strauss}

La antropología estructural de Claude Levi-Strauss (1908) resulta un tanto más compleja, tanto por la diversidad de influencias que la recorren, como por las transformaciones que se producen a lo largo de sus obras. En primer lugar encontramos su formación académica, bajo la densa atmósfera de un racionalismo humanista del que dicho autor quería apartarse. Su rechazo se dirigía hacia la fenomenología, el bergsonismo, el neokantismo, y el existencialismo, principalmente por lo que él consideraba un antropocentrismo radical, que giraba en torno a la figura del hombre y su problematización bajo los conceptos de sujeto, conciencia y libertad. Levi-Strauss cuestionará dicho sujeto y su valor de centro o punto de partida en las producciones culturales y simbólicas, para situarlo como mero efecto de una estructura inconsciente que, a modo de estructura lógica, lo produce como tal. Desde Descartes y pasando por Kant, Hegel, Husserl y contemporáneamente Sartre, el humanismo racionalista configuraba un campo hegemónico a nivel académico, del que Levi-Strauss se desprende mediante la transposición del modelo fonológicoestructuralista del "Círculo Lingüístico de Moscú" al campo de la etnología, bajo la ayuda de su amigo y colega Roman Jackobson. A través del mismo, pretendía llegar a una concepción positiva y científica de la cultura, aislando un objeto discreto de la misma forma que Martinet, Trubetzkoy, Jackobson y Sassure. En el caso de Sassure se trata de la lingüística como disciplina independiente y autónoma, al aislar la lengua (sistema formal de oposiciones binarias constituidas en base a unidades de significación mínima o signos) del habla (ejecución concreta del acto de comunicación, que abarca tanto los fenómenos psíquicos, como fisiológicos y fisicos). La fonología de Jackobson y Trubetzkoy parte de este influjo sassuriano, para aislar la fonología de la fonética. Mientras que esta última estudia los sonidos como unidades de carácter físico, la fonología recurre a un análisis estructural, donde cada fonema se define en relación a un valor diferencial con otros fonemas. El fonema sería entonces la unidad significante del signo lingüístico; sin significado pero inmersa en una estructura de relaciones diferenciales que a nivel del significante influirían sobre el significado y por ende sobre la significación. Se trataría entonces, de un fenómeno lingüístico-estructural y no físico, fonético o psicológico. La transposición de este modelo fonológico al campo de la antropología es realizada en principio sobre el estudio de los sistemas de parentesco, para luego extenderse al terreno de la historia, el ritual, la religión y, principalmente, el mito. Su primera aparición se realiza en la prestigiosa revista Word, en un artículo titulado El análisis estructural en lingüística y en antropología (1945), que presagia su extensa e importante obra Las estructuras elementales del parentesco (1949). El método establece una unidad mínima: mientras en la lingüística estructural se trataba del signo, en el estudio etnológico de las estructuras de parentesco será el átomo de parentesco. Partiendo y afinando el análisis de Radcliffe-Brown sobre el avunculado, Levi-Strauss establece una unidad mínima que, al igual que el signo lingüístico, se compone partiendo de la conjunción de relaciones diferenciales que constituyen términos (cosanguinidad, alianza y filiación, que constituirían los términos hermano-hermana, esposo-esposa, padres-hijos) y no a la inversa, o sea, términos que constituyen relaciones. A partir de esta unidad mínima, se desarrollarían los diferentes sistemas de parentesco, sean 
simples o complejos. El origen de esta estructura se encontraría en la prohibición del incesto, regla universal que permite a la humanidad el pasaje de la naturaleza a la cultura, al fundar una lógica excluyente, de intercambio de mujeres y, posteriormente, fonemas y bienes materiales. Es a través de la prohibición del incesto, que el hombre accede a una lógica excluyente de prohibiciones y permisiones en el terreno de lo sexual, posibilitando el intercambio de mujeres y por ende la constitución de una red de relaciones (alianza, cosanguinidad, filiación) que posibilitan la configuración de una trama social de nivel superior. Dicha operación se trasladará posteriormente a los intercambios de bienes, y es la que posibilita el lenguaje y lo simbólico, a través de la configuración de una estructura lógica que actúa significando las diversas experiencias humanas. Dicha transposición del modelo fonológico jacokbsoniano no estuvo libre críticas, sobre las que Levi-Strauss tuvo que reelaborar y afinar conceptos, influenciado bajo la popularidad de la cibernética de Wiener, la teoría de los juegos de Von Neumann, entre otros.

La transposición en el terreno de los mitos se establece a partir de La estructura de los mitos (1955), se desarrollará posteriormente bajo una concepción dialéctico-estructuralista (La gesta de asdiwald, El pensamiento salvaje) y culminará en una suerte de metaestructuralismo bajo la serie de Mythologiques, escritas entre 1964 y 1971. En un comienzo se procede de manera análoga a los estudios sobre parentesco. Se establece la unidad mínima del sistema, en este caso los mitemas. Estos estarían inmersos en el lenguaje, aunque su forma diferiría del mismo, pues sus unidades constitutivas compondrían un grado más alto de complejidad. Citando a Barthes, para evitar ciertos rodeos:

"...el mito es un sistema particular por cuanto se edifica a partir de una cadena semiológica que existe previamente: es un sistema semiológico segundo. Lo que constituye el signo (es decir el total asociativo de un concepto y de una imagen) en el primer sistema, se vuelve simple significante en el segundo" (Barthes, 1997, p. 205)

O sea que el mito tomaría prestados los signos lingüísticos (significante + significado) y los utilizaría en calidad de significantes, para establecer sus propias configuraciones semiológicas. Dichas unidades se compondrían de cadenas de signos relativas a acontecimientos que suponen una temporalidad, pero que conforman una estructura permanente, ahistórica. El mito toma acontecimientos históricos que pliega a su propia estructura, pretendiendo cierta ahistoricidad. De esta forma la sincronía estructural absorbe la diacronía del acontecer, y las diferentes variantes del mito se conciben a sí mismas como "el original" y no como variaciones estructurales producto de las sucesivas reabsorciones del acontecer. El mitólogo se encargará entonces del análisis de dichas transformaciones, de acuerdo al método estructural-comparativo que superponga las versiones que el etnólogo posea a mano. Lo que importaría entonces serían los mecanismos de transformación y las articulaciones lógicas que se establecen, y que demuestran que todo pensamiento mítico, es lógico, racional y estructural. Se trata nuevamente de una reivindicación del primitivo como ser racional, concepción central en el pensamiento antropológico de LeviStrauss, en oposición a Levi-Bruhl y su concepción de una mentalidad 
prelógica. Con La gesta de Asdiwal (1959) el análisis estructural adopta consigo un método dialéctico que incluye al mito en su relación con los diferentes niveles en los que actúa -geográfico, económico, sociológico-, lo cuál integra al análisis de las variaciones mitológicas una perspectiva extrínseca a las mismas. En cuanto a los fenómenos estrictamente "religiosos", nunca se le dedica un estudio directo, por lo que se habla de cierta hostilidad o indiferencia frente a los mismos, aunque también podría ser consecuencia de la dificultad que ofrece el análisis estructural en su aplicación sobre sistemas de carácter más histórico o diacrónico. Sin embargo recordemos que la distinción realizada entre "pensamiento salvaje" y "pensamiento domesticado", remite a dos modos de estructurar las producciones narrativas, y que en el caso de Levi-Strauss, su obra contempla e investiga sobre las primeras, relegando las otras a un segundo plano.

En el caso de la magia, las primeras reflexiones se centran sobre el problema de la eficacia simbólica y la importancia de atribuir un sentido a las distintas experiencias que atentan contra la estructura del grupo en cuestión. A diferencia de la ciencia, que busca el sentido de un problema en la realidad objetiva y sus cadenas causales, la magia opera articulando las experiencias al sistema estructural de la sociedad en cuestión. En casos de integridad física (enfermedades, dolores intensos), crisis del desarrollo humano (partos, puerperios), violaciones de normas o códigos, comportamientos extraños, o bien catástrofes naturales, el hechicero o "shamán" ofrece una interpretación que permite la absorción del acontecimiento en la estructura, que codifica y significa la realidad social en cuestión. De esa manera las prácticas "shamánicas" significan aquellos estados que de otro modo se ofrecerían confusos y desorganizados para la conciencia:

“...pensamiento patológico y pensamiento normal no se oponen, sino que se complementan. En presencia de un mundo que ávidamente quiere comprender, pero cuyos mecanismos no alcanza a dominar, el pensamiento normal exige a las cosas que le entreguen su sentido, y éstas rehúsan; el pensamiento llamado patológico, por el contrario, desborda de interpretaciones y resonancias afectivas, con las que está siempre dispuesto a sobrecargar una realidad que de otro modo resultaría deficitaria... La colaboración colectiva en la cura shamanística establece un arbitraje en estas dos situaciones complementarias... es preciso que, por una colaboración entre la tradición colectiva y la invención individual, se elabore y se modifique continuamente una estructura, es decir, un sistema de oposiciones y correlaciones que integra todos los elementos de una situación total donde hechicero, enfermo y público, representaciones y procedimientos, hallan cada uno su lugar." (Levi-Strauss, 1997, p. 207-208).

La "cura" tendría sus bases en la eficacia simbólica del esquema en cuestión, independientemente de su correspondencia con las causalidades objetivas o científicas (eficacia sobre lo real). Consistiría principalmente en volver inteligible una situación problema, haciéndola soportable al espíritu y por lo tanto tolerable, mediante un sistema coherente que vectorializa las diferentes experiencias que de otro modo se ofrecerían caóticas e insoportables. 
Por último nos remitiremos a las diferencias entre pensamiento científico y pensamiento mítico, tal y como se expone en El pensamiento salvaje. Es allí que establece la ya muy conocida distinción entre el pensamiento salvaje de la magia y el pensamiento científico. En una primera instancia, se pone en evidencia la tesis fundamental de su estructuralismo: ambos pensamientos tanto el del salvaje como el del hombre científico- se construyen a partir de premisas lógicas y una necesidad de orden, necesidad que caracteriza a todo tipo de pensamiento. Las diferencias entre ambos estarían entonces no en la ausencia o presencia de determinadas categorías lógicas, sino en el modo en que uno y otro se relacionan dialécticamente con el devenir histórico-cultural. El pensamiento salvaje absorbería el acontecimiento a modo de un programa cibernético, mediante un feedback o circuito de retroalimentación positiva donde se vuelve siempre a un supuesto estado cero. De ahí la importancia del origen y la tradición en este tipo de sociedades. Se trataría de una primacía de lo sincrónico, que daría por resultado la ilusión de inmutabilidad, característica de lo que denominamos "sociedades frías" o ahistóricas. El pensamiento mitológico postula un determinismo global e integral, donde todo se relaciona a modo de fotografía, sin las discriminaciones de niveles diferenciados, propias del pensamiento científico. Se trata de una lógica de lo concreto, dónde se establece una estructura cohesionante, con los medios que se encuentran a disposición, tejiendo signos que se encuentran a disposición y transformándolos en significantes para de ese modo expresar metafóricamente mediante la creación de significaciones de segundo grado que puedan cohesionar e integrar diversos órdenes de la experiencia. Así, mediante los animales, los astros 0 los dioses, se establecen relaciones que metafóricamente aluden y estructuran al orden de lo social y lo cognoscitivo. A esta actividad Levi-Strauss la designa bajo el nombre de Bricolage, "lógica de lo concreto", basada en la utilización de signos que en forma metafórica conforman una estructura simbólica y cognoscitiva.

El bricoleur actúa entonces de manera ahistórica, metafórica y concreta, a diferencia del científico que utiliza un pensamiento de carácter histórico, metonímico y abstracto. Este último opera mediante la creación de modelos, que suponen la utilización de conceptos abstractos que sustituyen e intentan explicar la realidad, bajo reglas de causalidad (relación efectos-causas) que configuran y significan el acontecimiento: “...el pensamiento mítico, ese bricoleur, elabora estructuras disponiendo acontecimientos, o más bien residuos de acontecimientos, en tanto que la ciencia, 'en marcha' por el simple hecho de que se instaura, crea, en forma de acontecimientos, sus medios y sus resultados, gracias a las estructuras que fabrica sin tregua y que son sus hipótesis y teorías. Pero no nos engañemos: no se trata de dos etapas, o de dos fases, de la evolución del saber, pues las dos acciones son igualmente válidas". (Levi-strauss, 1964:43). Se trataría entonces de una división que encuentra resonancias con el primitivo pragmático de Malinowski, o bien la distinción entre operaciones concretas y operaciones abstractas realizada por Piaget y su psicología cognitiva, con la excepción de que se elimina cierto evolucionismo filo-ontogenético postulado por ambos autores, relativizando y validando la función de ambos métodos de acuerdo a las sociedades a las que se dirigen. 


\section{Conclusiones}

Vemos entonces cómo el desarrollo de esta línea antropológica hunde sus problemáticas en cómo lograr una interpretación o conocimiento del primitivo desde su distancia con la sociedad occidental moderna. Surge la cuestión de la lógica, la razón y la ciencia, y que continuidades y discontinuidades podemos trazar en relación a esas otras sociedades, sobre las que la etnografía debe rendir cuentas. El pensamiento antropológico que recorre los autores analizados, parte de la premisa de una unidad instrumental en la razón humana: todos los seres humanos están en propiedad de la razón, pese a ciertas diferencias que cada autor plantea a su manera y de acuerdo a las influencias y observaciones que dispone. Tylor plantea la discontinuidad bajo la confusión de una dimensión imaginaria con la de lo real-perceptivo; Frazer bajo un pensamiento psicologisista-proyectivo y otro objetivo-experimental; Malinowski bajo uno concreto y otro abstracto, Levi-Strauss hablará de un bricoleur y el pensamiento científico metonímico. Se impone a su vez la polarización entre una dimensión afectiva y otra racional que estructura a la primera de distintas maneras, otorgando un sentido a la existencia y un cauce a las afecciones. El primitivo utilizará mecanismos distintos al hombre de ciencia; su forma de controlar la realidad y las pasiones humanas sería mucho más precaria por lo que incurriría en diversos errores o bien creencias anestesiantes (con algunas excepciones, como por ejemplo Levi-Strauss, que considera la diferencia dentro del orden lógico y estructural).

Vimos a través de diferentes autores el comienzo de un proceso de reflexibilidad en torno a la religión y su relación con la emergencia del pensamiento científico-moderno, que exige ciertas diferenciaciones epistemológicas, antropológicas, y psicológicas. El advenimiento de un nuevo tipo de pensamiento que comienza a reflexionar en torno de sí, sobre cuáles son sus bases lógicas, psicológicas, sociales. Una búsqueda de legitimidad social, construyendo un conjunto de diferenciaciones que comprehendan sus mecanismos y los sitúen en la cúspide del desarrollo universal, en una suerte de necesidad y destino histórico. El eje evolutivo parte de una dicotomía entre dos polaridades que se relacionan a modo de un continuum. Por un lado un polo más cercano a lo afectivo; en el otro un polo racional, abstracto, una especie de sujeto trascendental, que opera en dialéctica con la realidad mediante el ensayo y error. En aquellas culturas más cercanas al polo afectivo, los afectos irrumpen en forma mucho menos controlada, debido a mecanismos aún precarios en el hombre. Entre dichos mecanismos predomina la proyección, de la que deriva el animismo, la antropomorfización de la naturaleza y la creencia en un Dios padre. Dicha proyección responde a la necesidad de situar en algún lado una omnipotencia que en eslabones anteriores no es posible abstraer o abandonar, debido a cierta inmadurez en el desarrollo de una integridad mental que apunte al realismo. Es por ello que el aparato cognoscitivo del primitivo y del infante $-\mathrm{y}$ del neurótico también- se enreda bajo el tejido ilusorio de la dimensión imaginaria, así como alrededor de sus deseos intensos por que las cosas ocurran de una manera tal; una necesidad de control que no contempla de forma objetiva los resultados en su choque con la realidad y su consecuente frustración. Y aunque el primitivo o el infante no dejan de tener -bien en potencia o bien en ciertos aspectos tanto 
cuantitativos como cualitativos- la capacidad de análisis lógico y raciocinio, se enfatiza en su cercanía al polo afectivo, o bien la predominancia de un pensamiento concreto -léase como percepción y precepción escasamente mediatizada- en sus actividades cognitivas, situándose un eslabón por debajo de la formalización científica -metonímica o abstracta-, mucho más cercana a la realidad mecánica del mundo.

Bajo este eje dualista cada autor desarrolla a su manera el problema de la racionalidad. El caso de Levi-Strauss por ejemplo, resulta muy lejano a la ingenuidad con la que Tylor y Frazer describían al primitivo, marcando por sobre todo una distancia a cualquier concepción que pretenda ver al pensamiento del "primitivo" como forma infantil, inmadura o arcaica. Sin embargo el eje evolutivo que marcan estos dos polos resulta pertinente pues sobre él se construyen tanto las subversiones como las críticas o los refinamientos del pensamiento secular moderno. Esta secularidad actúa alrededor de un núcleo racionalista, partiendo de la creencia en su inevitabilidad histórica. En ser la última capa en el desarrollo humano, que emerge en sustitución de cierta irracionalidad humana, encarnada bajo la figura de la religión.

\section{Bibliografía citada}

BARTHES, R. (1997) Mitologías. Siglo XXI Editores, México.

CARRACEDO, J. R. (1976) Levi-Strauss. Estructuralismo y ciencias humanas. Ed. Istmo, Madrid.

DE WAAL, A. (1975) Introducción a la antropología religiosa. Verbo Divino, s.l., 1975.

DURKHEIM, E (1993) Las formas elementales de la vida religiosa. Alianza Editorial, Madrid.

FRAZER, J. G. (1998) La rama dorada. FCE, México.

LEVI- STRAUSS (1964) El pensamiento salvaje. FCE, México.

-- (1965) El totemismo en la actualidad. FCE, Mexico.

-- (1997) Antropología estructural. Ediciones Altaya, Barcelona.

MALINOWSKI, B. (1985) Magia, ciencia y religión. Planeta- Agostini, Barcelona.

-- (1978) Una teoría científica de la cultura y otros ensayos. Sudamericana, Buenos Aires.

MAUSS, M. (1967) Introducción a la etnografía. Istmo, Madrid.

TYLOR, E. B. (1977) Cultura primitiva. Editorial Ayuso, Madrid. 